\title{
استخدام الرسم والتعبير الحر فى تنميه ههارات التواصل لدى اطفال متلازمه داون
}

\author{
إعلداد \\ د. محسـ محمد العزازكى \\ مدرس الرسم والتصوير بقسم التربيه الفنيه \\ بكليه التربيه النوعيه جامعه المنصوره \\ | . د. عايده عبد الحميد محمد ابو القطط \\ استاذ علم نفس التربيه الفنيه والعلاج بالفن \\ ورئيس قسم علوم التربيه الفنيه (سابقا) \\ بكليه التربيه الفنيه جامعه حلوان
}

نسمه محمود علحس لمحمد

باحث ماجستير

مجلة بحوث التربية النوعية ـ جامعة المنصورة

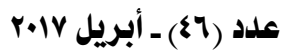




\section{استخدام الرسم والتعبير الهر فى تنسيه ههارات التواصل}

\section{لدى اطفال متلازهه داون}

$* * *$ سممه محمود عللمحمد
$* *$

د . مرممد العزازي
I .د .عايدهعبد الحميد محمد

يتناول البحث الحالى مفهوم متلازمـه داون واعراضها واسبابها وخصائصها وكيفيه تنـميه

مهارات التواصل اللفظى وغير اللفظى والتعبير الحر بالرسهم لديهم من خلال برنامهج فنى تشكيلى دئى

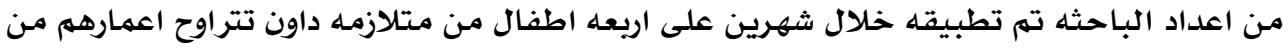

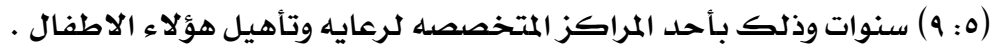

واستتنتجت الباحثه من خلال هذا البحث مجموعه من الاساليب الفنيه التربويه التى يمكن

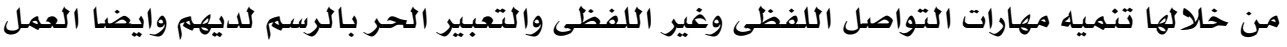

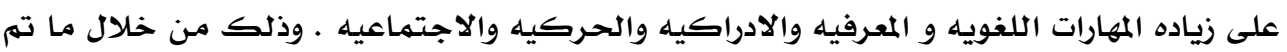
اثباته من فروض الدراسـه.

هقدهـه

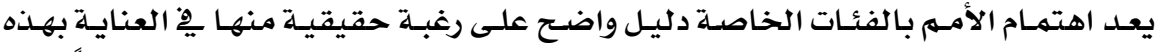

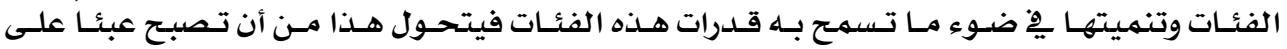

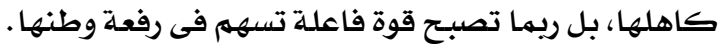

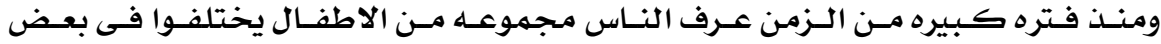

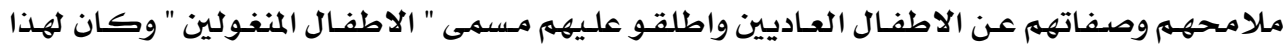

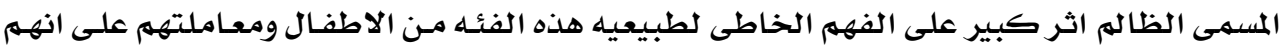

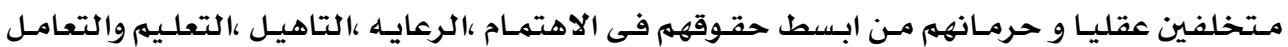

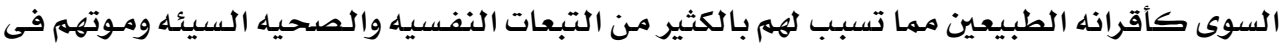

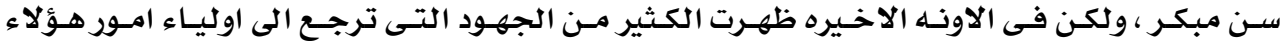

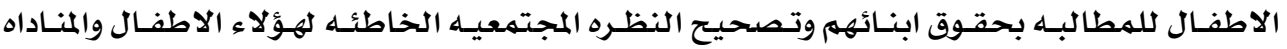

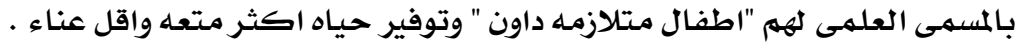
وصـنفت متلازمــه داون تحست بنـــ الاعاقـه الفكريـه والتـى تكـون مـن اكـبر المشكلات التـى تواجهمه صعوبه التواصل الاجتماعى واللفظى والذى ينقسهم بين اللغه الاستقباليه واللغهل التعبيريـه 
فاللغه والكلام وسيله هامـه تسـاعد الفرد فى عمليه التوافق الاجتماعى حيث هى وسيلـه التفـاهم بـين.

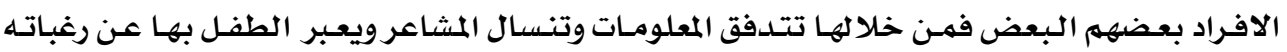

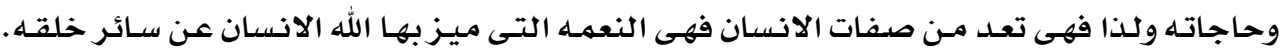

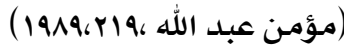

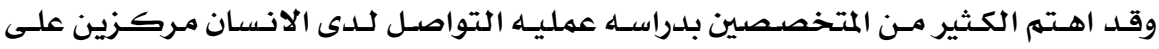

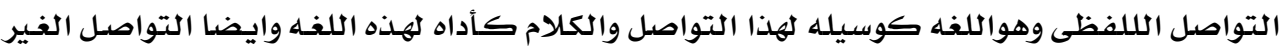

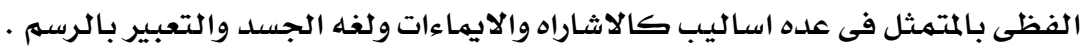

فتقول (عبله حنفى ، 1991)ان الفنون التشكيليه والرسسم ليس للانسـان العـادى فقط ،وانهـا

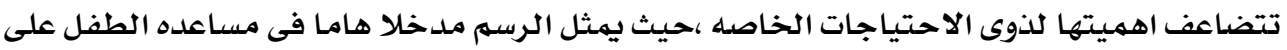

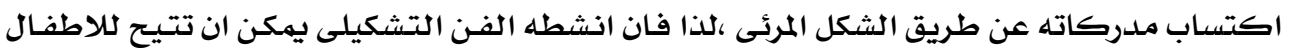

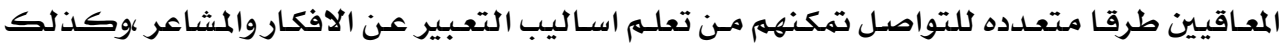

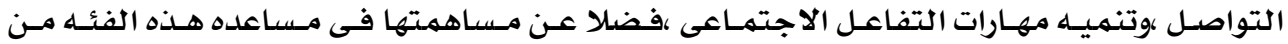

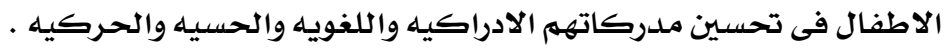

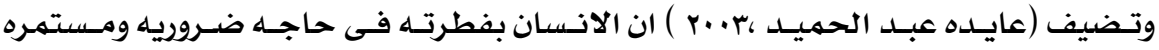

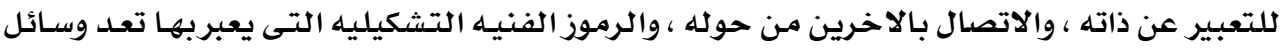

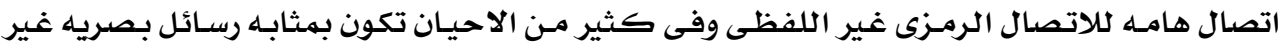
لفظيه

\section{مشكاله البحث}

تتمركز مشكله الدراسه حول الاجابه على تساؤلين ا ـ مادور الرسم فى تنميه مهارات التواصل " اللفظى وغير اللفظى لدى عينـه مـن اطفـال متلازمـهـ داون؟ ץ. هل اطفال متلازمـه داون لديهم القدره على التعبيرمن خلال الرسهم الحر ؟

اهدف الدراسه

ا.تنميه مهارات التواصل (اللفظى وغير اللفظى ) لدى عينه من اطفال متلازمـه داون .

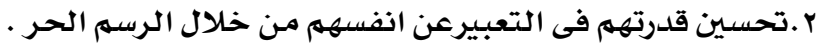

\section{اهميسه الدراسه}

ا ـ قـد تسهـم الدراسـه فى تحسن مهارات التواصـل اللفظى وغير اللفظى لـدى الاطفـال متلازمسه 
ב-

r. توجيـه عنايـه الابـاء والقـائمـين على رعايـه هـذه الفئــه مـن الاطفـال على دور الفـن فى مسساعده

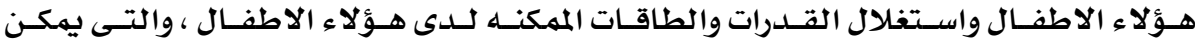

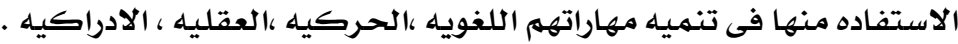

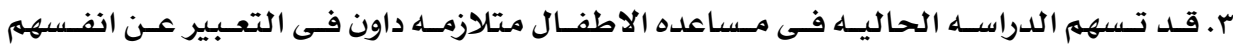

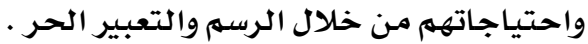

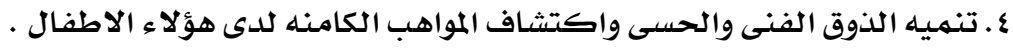
ه. قله الدراسات التى تناولت دور الفن التشكيلى فى تنـميه مهارات الاطفال متلازمـه داون .

\section{هدود البمث}

تم تطبيق البحث فى مـركز انـا موجـود لرعايـه وتأهيل الاطفـال ذوى الاحتياجـات الخاصـهـ

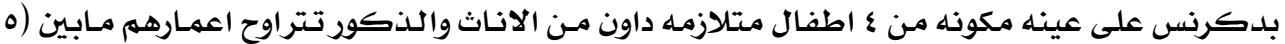
(9: بنوات (9)

\section{年}

Drawing الرسيم

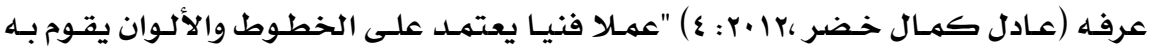

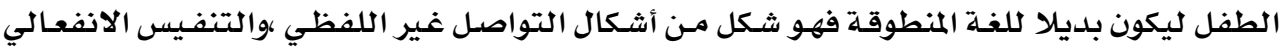
وانعكاس حقيقة مشاعرهم نحو أنفسيكه والآخرين ".

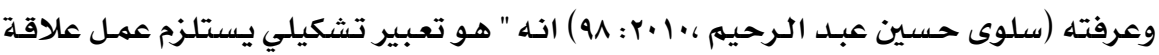

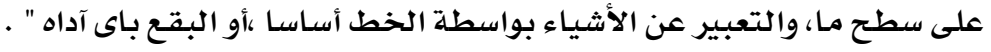

$$
\text { التعريف الاجرائى للرسيم }
$$

هو احد مجالات الفن التشكيلي التي يستخدمها طفل متلازمـه داون ويكون بمثابـة اللغـة أو

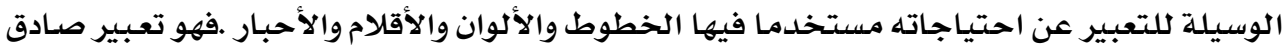

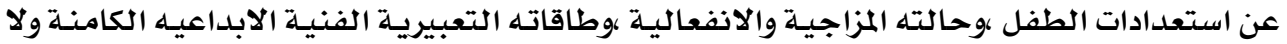

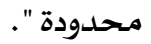
التقبير الحر

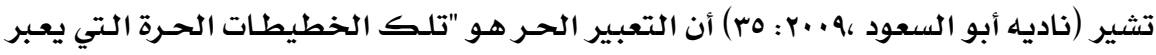

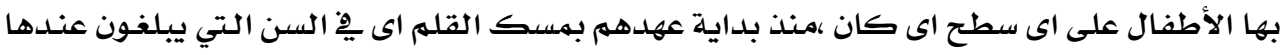

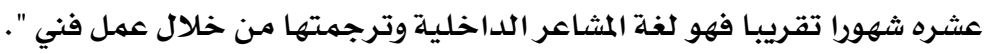
Communication Skills مهارات التواصل

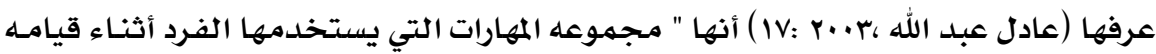

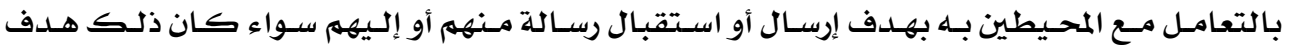




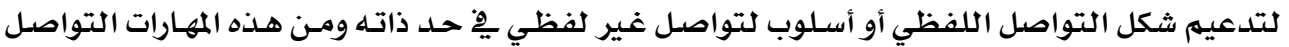

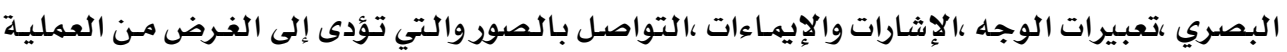
الاتصالية وهو نقل أفكار الفرد إلى المحيطين به الإنهار " .

$$
\text { التعريف الاجرائى }
$$

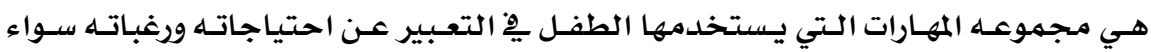

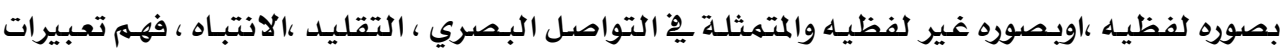

$$
\text { الوجـه ،التعبير بالرسهم. }
$$

متلازمه داوز Down's syndrome

عباره عن شذوذ خلقى مركب وشائع فى الكرموسوم ابنتيجه اختلال تقسيهم الخليه ويكون

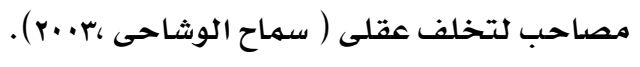

الاطار النظرى

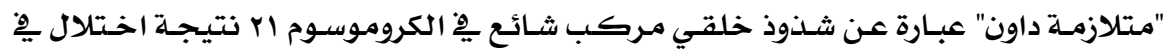

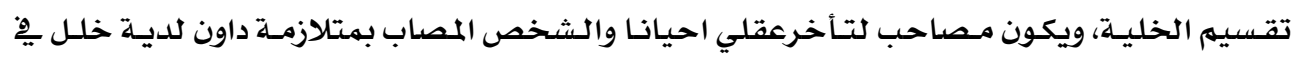

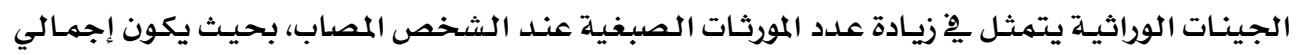

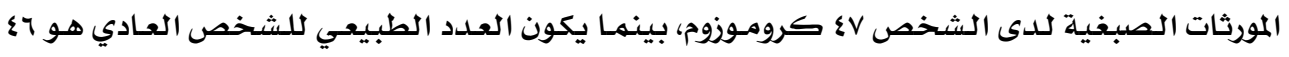

كروموزوم.

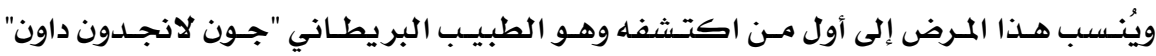

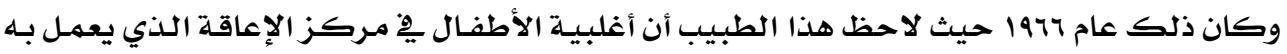

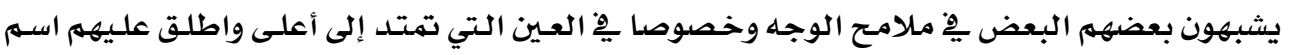

$$
\text { المنغوليين نسبة إلى العرق الأصفر المنغولي. }
$$

أنواع متلازمة داون:

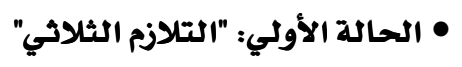

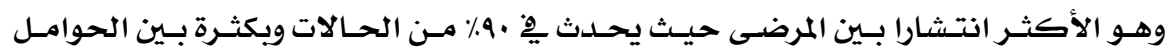

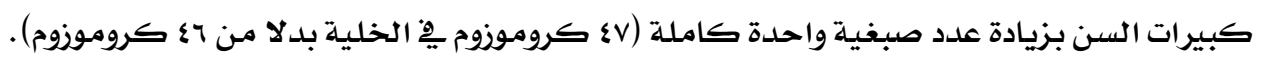

\section{• الحالة الثانية: الانتقائي"تبدل وضعية الكروموزوم"}

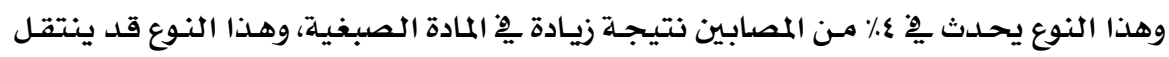

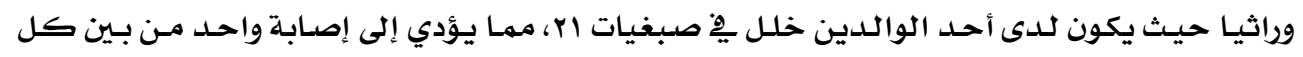

ثلاثة أطفال ينجبون قبلهم. 
• الحالة الثالثة: الفسيفسائي"موزاييك"

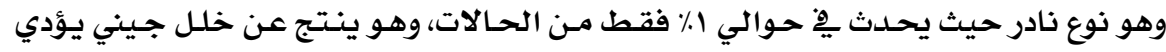

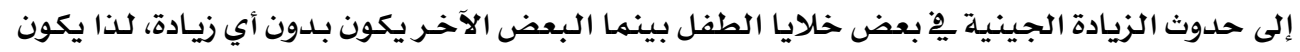

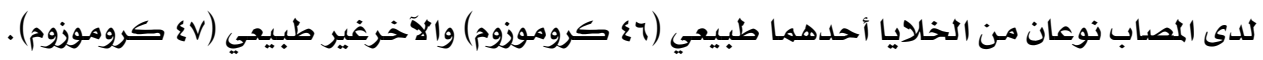
اسباب حدوث متلازمة داوز:

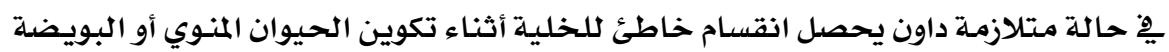

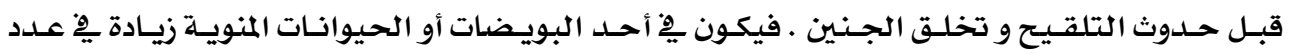

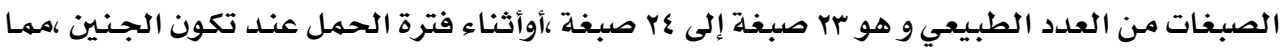

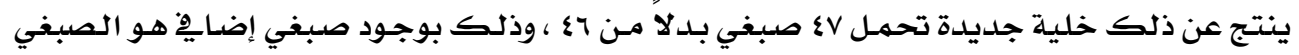

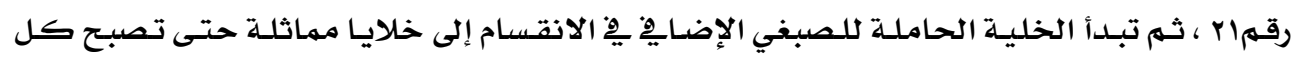

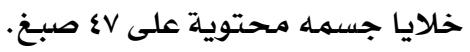

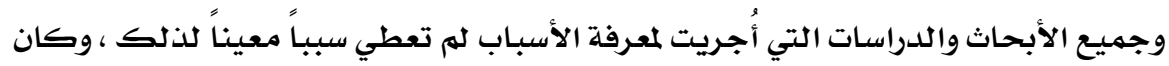

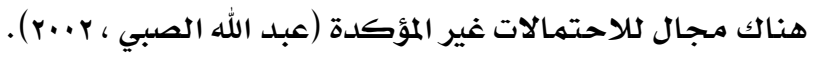
نذكر منها :- نانسا

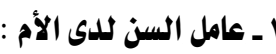

يزداد احتمال حدوث الحالة بزيادة سن الأم ، فقد وجد أن نسبة الإصابة بمتازلازمـة داون تزداد

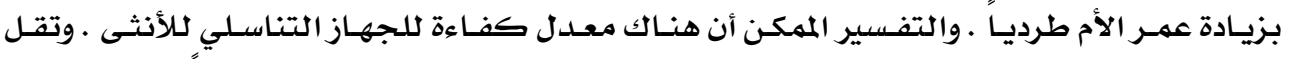

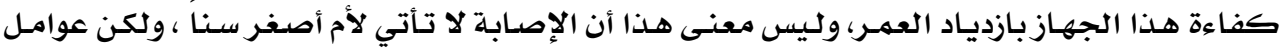

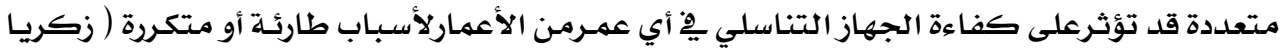

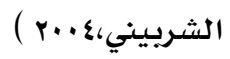

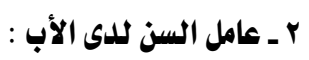

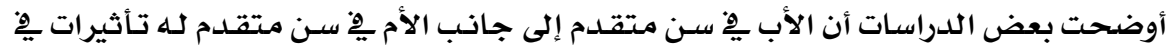

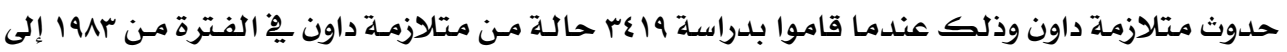

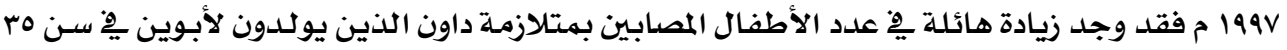

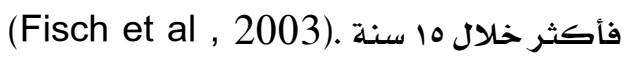

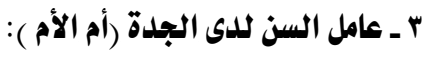

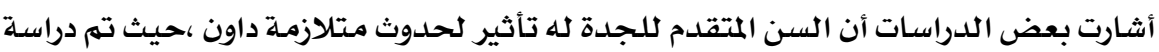

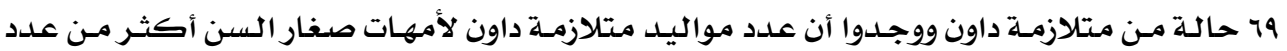

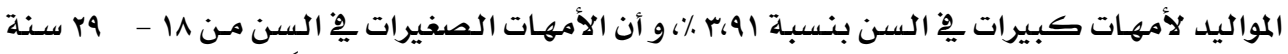

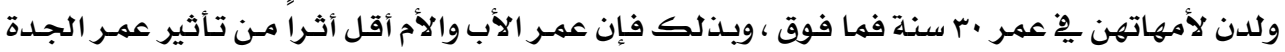
كلأم. (2006، Malini,Ramachandra). 


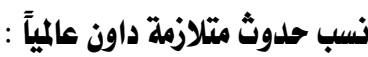

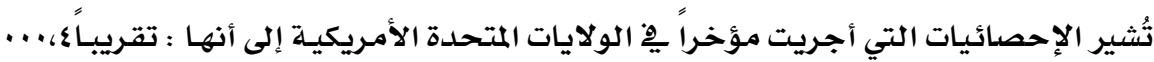

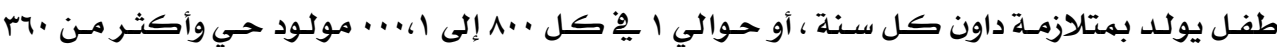

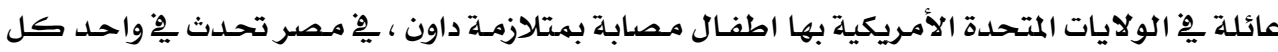
Tگه مولود حي

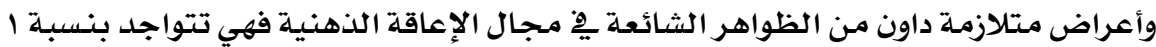

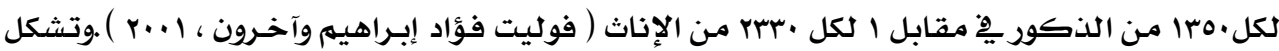

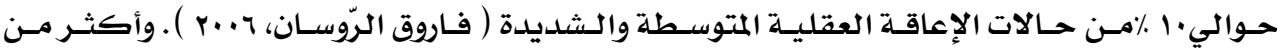

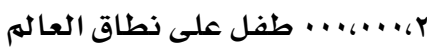

\section{الخصائص الأساسية للمصابين بمتلازهة داون:}

\section{الخصائص الجسمية والاكلينيكية:}

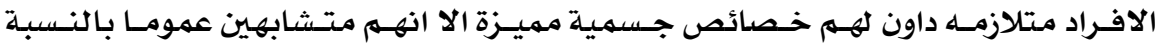

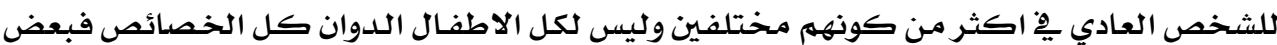
منهم لديه قليل منها والبعض لدية معظم خصائص الدوان وتتضمن الخصائص الاتي: رقبة عريضة قصيرة.

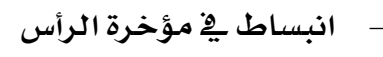

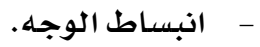

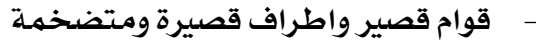

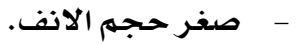

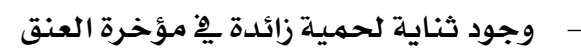

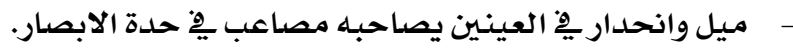

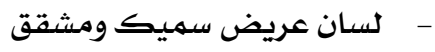

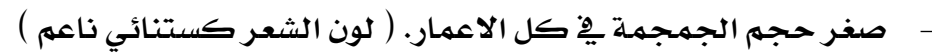

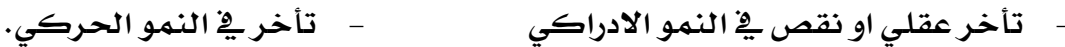

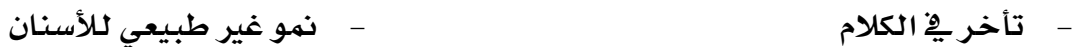

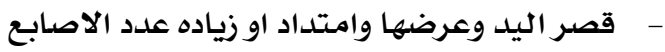

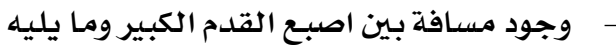

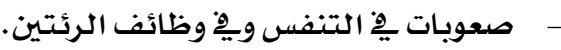

خصائص النمو للداوز:

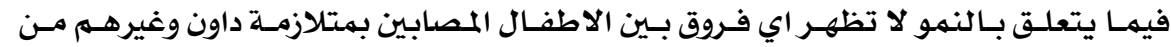

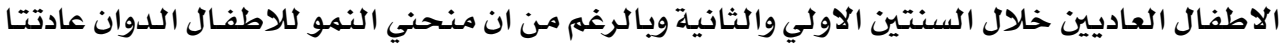

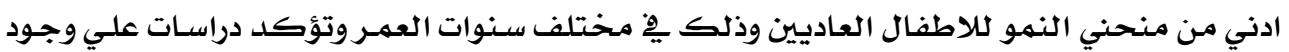

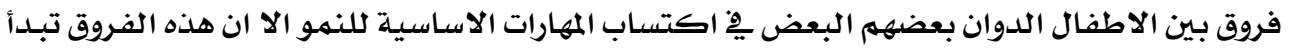




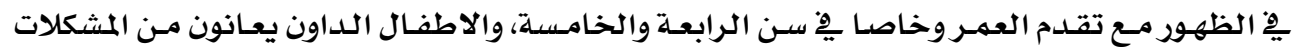
النمائية التالية :-

$$
\begin{aligned}
& \text { • صعوبات ِِّ الحواس المختلفة وخاصا حاستي اللمس والسمع. }
\end{aligned}
$$

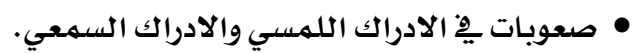

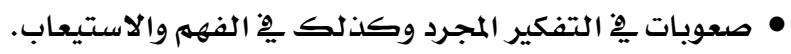

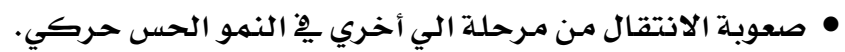

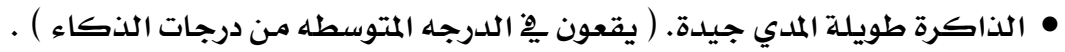

\section{الخصائص السلوكية والاجتماعية:}

• يتميز الاطفال المصابين بمتلازمة داون بالخصائص السلوكية والاجتماعية التالية :

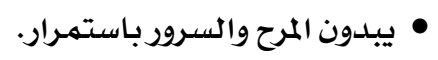

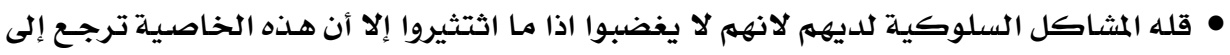

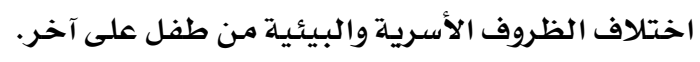

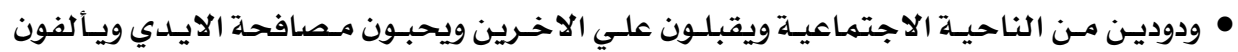

$$
\text { الغرياء. }
$$

\section{كيفية التصرف علي خطر الحمل في طفل داون: \\ التحاليل التشخيصية لمتلازمة داون:}

عينـة مـن السـائل المحيط بـالجنـين : يتم سـحب عينـة مـن السـائل المحيط بـالجنـين بواسطة

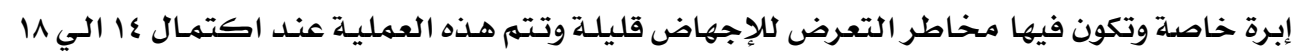

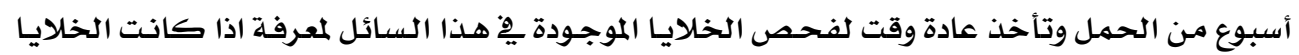

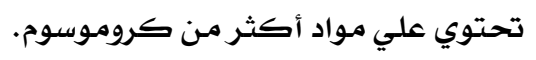

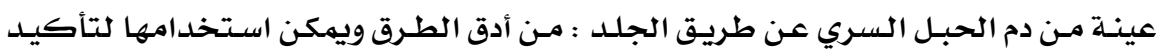

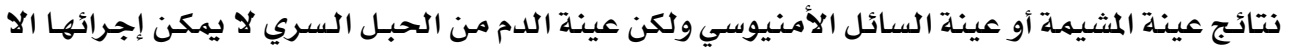

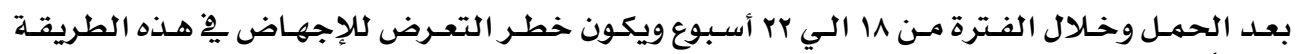
كبيرا.

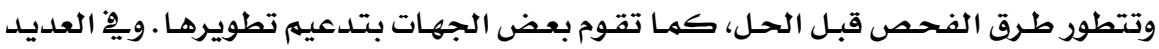

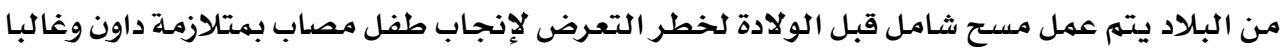

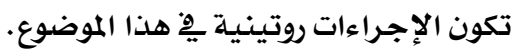

عينة من المشيمة: Chorionic Vills Sambling (CVS) يتم سحب عينة من المشيمة يِي

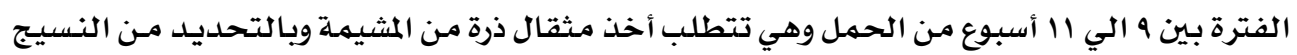

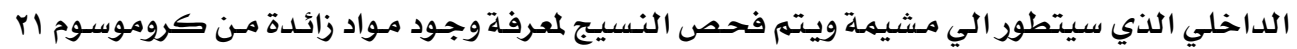

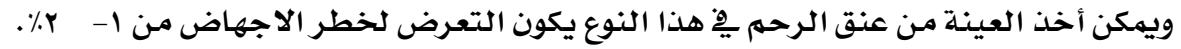


الرعاية الصحية للأطفال المصابين بمتلازمة داون :

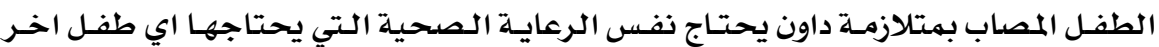

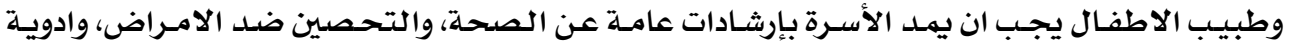

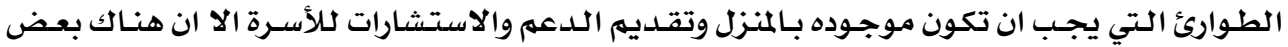

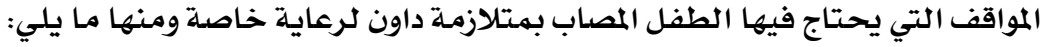

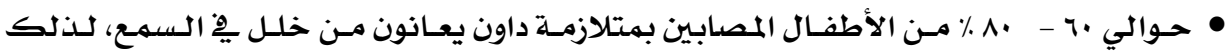

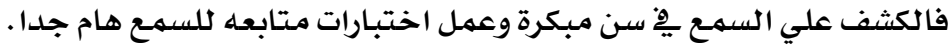

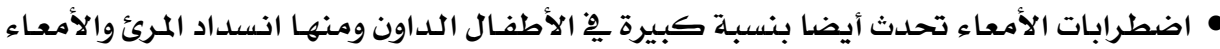

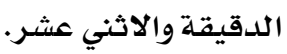
• الأطفال الداون يعانون من مشكلات يِّا العين أكثر من الأطفال الطبيعيين.

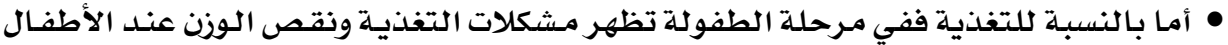

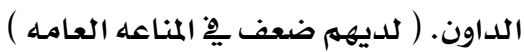

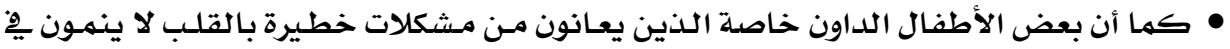

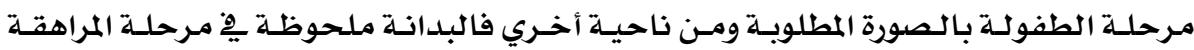
والبلوغ نتيجة زيادة مخزون الدهون.

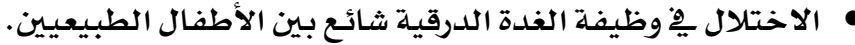

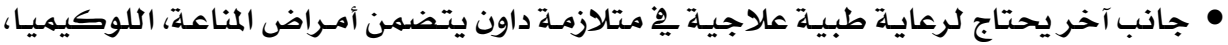

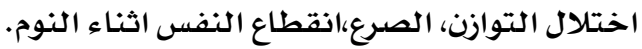
الفن التشكيلى ومتلازمه داون

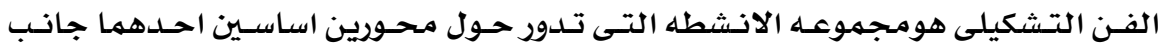

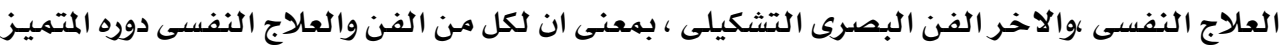

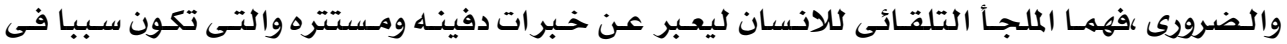

فالانشطه الفنيه لها دور هام فى بنـاء شخصيه الطفل ،فالنشاط الفنى يساعد الفرد على

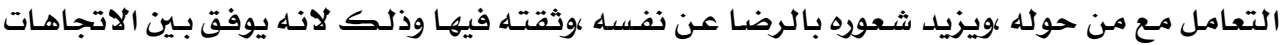

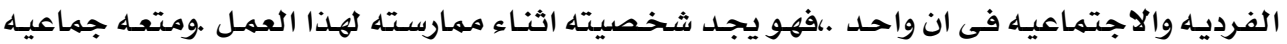

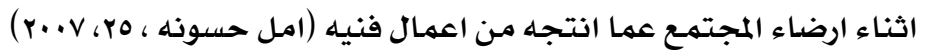
فوائل الانشطه الفنيه فى علاج ذوى الاحتياجات الخاصه عامه ومثلازمه داوز خاصه ألهاء ا ـ تكفل الانشطه الفنيـه فرصـا كثيره لهؤلاء الاطفـال لتحقيق ذواتهمه والتقليـل مـن شعورهم

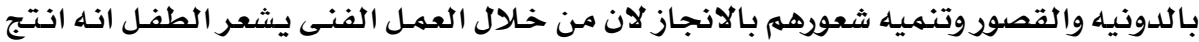




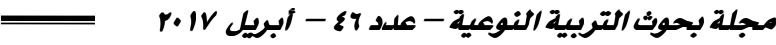

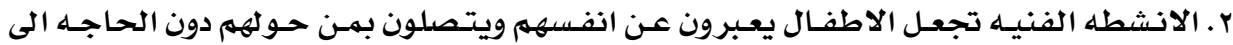

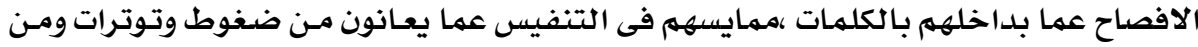

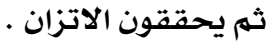

r. تساهم الانشطه الفنيه العلاجيه في تنميه الاستعدادات والمهارات الجسميه اليدويـه والوظائف

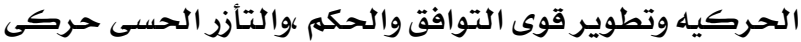
ع. تساهم الانشطه الفنيه العلاجيه فى تتميه الاستعدادات والوظائف العقليه كالانتباه والادراك والذاكره والتمييزوالحفظ .

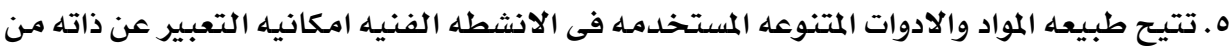

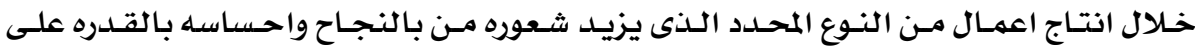

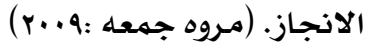

الاطار العهملى

تم تطبيق الايطار العملى فى مركز انا موجـود لرعايه وتأهيل الاطفـال ذوى الاحتياجـات

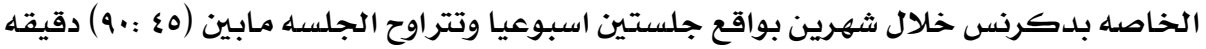
ادوات البمث • • • استماره دراسه الحاله " اعداد الباحثه"

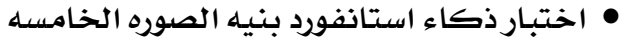
• مقياس مهارات التواصل اللفظى وغير اللفظى والتعبير الحر بالرسم " اعداد الباحثله"

الهدف العام للبرناهمج

يهـدف البرنـامج الى تنـميـه مهارات التواصـل اللفظى وغير اللفظى لـدى عينـه مـن اطفـال

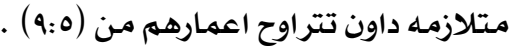

\section{الاهداف الاجرائيه للبرناهج}

• الاهداف السلوكيه

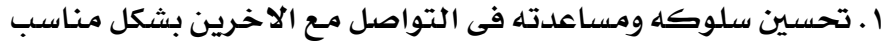

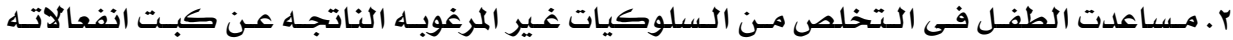
واحتياجاته • الاهداف الوجدانيه

ا ـ اطلاق الحريـه الكامله للطفل للتنفيس عن الطاقات العدوانيه بتوفير وسيله لاسـاط المشاعر

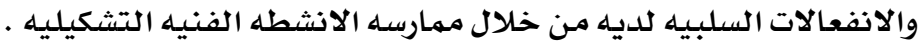

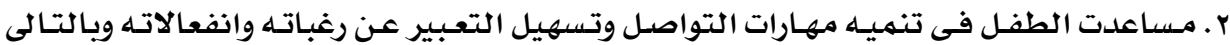

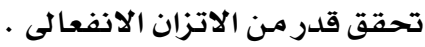


r. تعويـضـه عـن لغسه تواصـل غـير لفظـى بلديلسه عـن تواصـلـه اللفظـى فتتهـى شـعوره بالانتهـاء

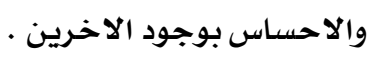

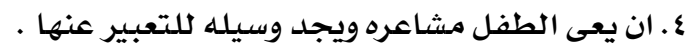

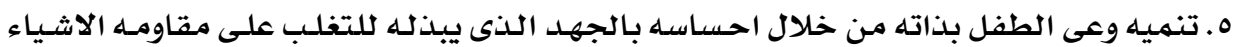

1. اتاحه الفرصـه امـام الطفل لانتـاج اعمـال يمكن ان تحظى بـالقبول والتقدير ممـا يشبـع حاجـهـ

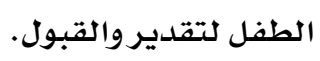

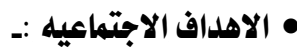

ا.مساعده الطفل فى الاندماج بشكل افضل فى المجتمع من خلال تنميه مهارات التواصل .

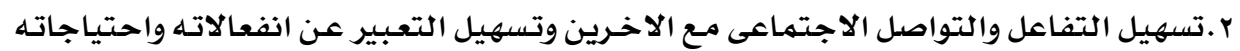

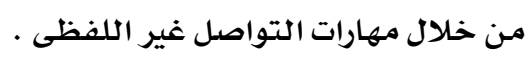

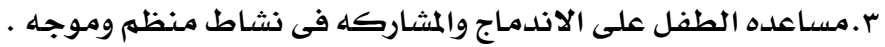

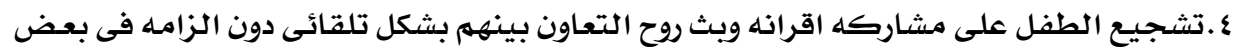

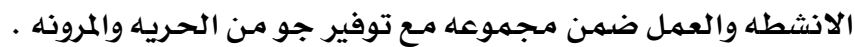

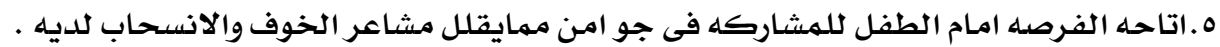

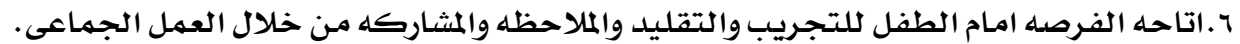

\section{• الاهداف المعرفيه}

$$
\begin{aligned}
& \text { I ز زياده قدره الطفل على التواصل البصرى . } \\
& \text { r. r. تنميـه قدرات الطفل على التركيز والطفل الانتباه. }
\end{aligned}
$$

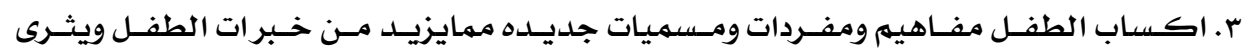

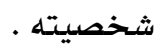

ع ـ تنميـه قدره الطفل على ادرالك نفسه والاخرين والبيئه المحيطه.

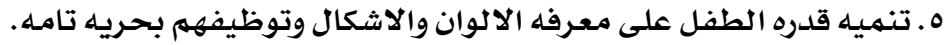

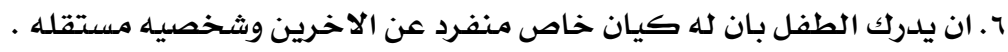

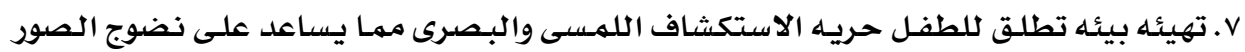
العقليه لدى الطفل عن الاشياء الاخرى .

\section{البرناهمج}

• • اللقاء الاول : (رسم وتلوين قطهة)

$$
\text { - " زمن اللقاء : هـ دقيقه اللقاء : فردى ل }
$$

• الادوات المستخدمه : ( اوراق بيضاء / قلم رصاص / اقلام تلوين خشب وفلومسترفسفوريه ) 


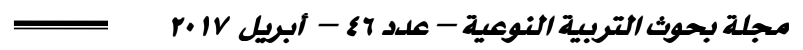

• اللقاء التانى : (تصويروتوليف خامات لنموذج قطه)

$$
\begin{aligned}
& \text { " زمن اللقاء: ·q دقيقه } \\
& \text { " نوع اللقاء : تنائى } \\
& \text { • الادوات المستخدمـه : }
\end{aligned}
$$

• (فرو اصـفر صـناعى ، مـاده لاصـقه ، قلـم فلومستر ، ورق كانسون ابـيض ، زرار احمـر ، شـريط

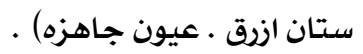

• اللقاء الثالث: ( الرسم الحر) بالالوان الاكوريليك

$$
\text { • • مده اللقاء :-9 دقيقه اللقاء }
$$

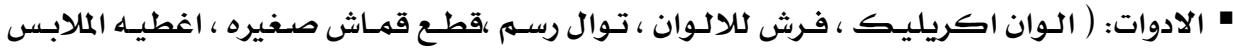

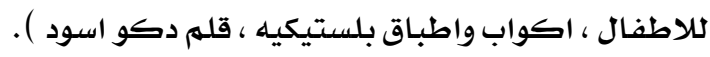

• اللقاء الرابع :حواسى

• مده اللقاء : •ج دقيقه

• توع الجلسه : بنائيه

• الخامات ( ورق كانسون ابيض ، ورق قص ولصق ، مقص ، قلم رصاص ).

• اللقاء الخامس : الرسم بالاصابع

$$
\begin{aligned}
& \text { " مده اللقاء :•7 دقيقه } \\
& \text { " نوع اللقاء : جماعي }
\end{aligned}
$$

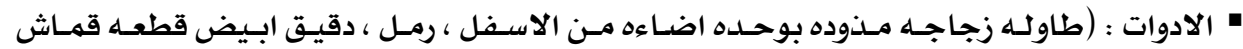

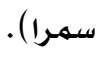

• اللقاء السادس: اكتشافى لنفسى

$$
\text { • • مده اللقاء : •7 دقيقه . }
$$

• الادوات : ( قهـاش ابـيض ، الـوان مـائيسه ، اوانسى لتخفيـف الالدوان ، اغطيسه لكلارضـيات ، اغطيـه

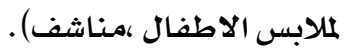

• التقاء السابع :رسم شجره

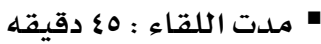

• نوع اللقاء : فردي 
• الادوات : ( ورق ابيض ، قلم رصاص ، الوان باستيل ، صور متعـدده لاشكال مـن الورود والاشــار

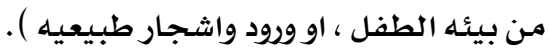

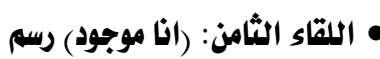

$$
\text { • • مده اللقاء :•ج دقيقه اللقاء : ثنائي }
$$

• الادوات : ( صوره شخصيه للطفل ، فرخ ورق نصبيان ، قلم دوكو ، الوان اكوريليك ، فورشـاه

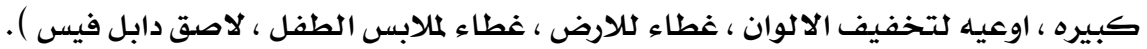

• اللقاء التاسع : انفعالاتى بالاقلام الفلومستر

$$
\text { • • مدت اللقاء : • ب دقيقه اللقاء : ثنائيه }
$$

• الادوات : ( ورق ابيض ، الوان فلومستر ، صوره فوتغرافيه لطفل ذاته التقت لـه وهـو فرحسان وهو

\begin{tabular}{|c|c|}
\hline متوسط المهاره للدى الاطفال & 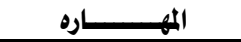 \\
\hline$\cdot, 0$ & التواصل اللفظى اللفظى \\
\hline صفر & التعبير الحر \\
\hline$\cdot, 0$ & التواصل غبر اللفظى \\
\hline
\end{tabular}

$$
\begin{aligned}
& \text { يبكى ). } \\
& \text { • اللقاء العاشر : قص ولصق } \\
& \text { " مده اللقاء : • ب دقيقه } \\
& \text { • نوع اللقاء : فردي }
\end{aligned}
$$

\begin{tabular}{|c|c|c|c|}
\hline التواصل غير اللفظى & التعبير الحر & التواصل اللفظى & الطفل / المهاره \\
\hline 1,07 & $\bullet, r$ & $r, q$ & $\dot{j}$ \\
\hline$r, I^{2}$ & $\cdot, \mathrm{YA}$ & $\cdot, 7$ & ك5 \\
\hline $1, r$ & $\cdot, \mathrm{A}$ & $r, q$ & ب \\
\hline I, rr & $\cdot, \mathrm{YA}$ & $\cdot, r$ & j \\
\hline
\end{tabular}

• الادوات : ( ورق ابيض ، ورق قص ولصق ملون ، مقص ، اقلام الوان، صور لاطفال فى حاله حزن

$$
\text { وفرح ). }
$$

متوسط المهارات فى الاختبار القبلى

متوسط الاستجابات لكل طفل فى الثلاث مهارات كالتالى 


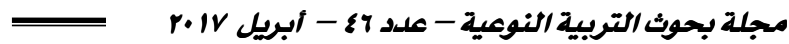
متوسط مجموع استجابات عينه البحث للثلاث مهارات للقياس البعدى

\begin{tabular}{|c|c|c|}
\hline التواصل غير اللفظى & التعبير الحر & التواصل اللفظى \\
\hline 1,79 & $\cdot, \mathrm{rq}$ & 1,0 \\
\hline
\end{tabular}

بهض صور التبربه العهمبيه
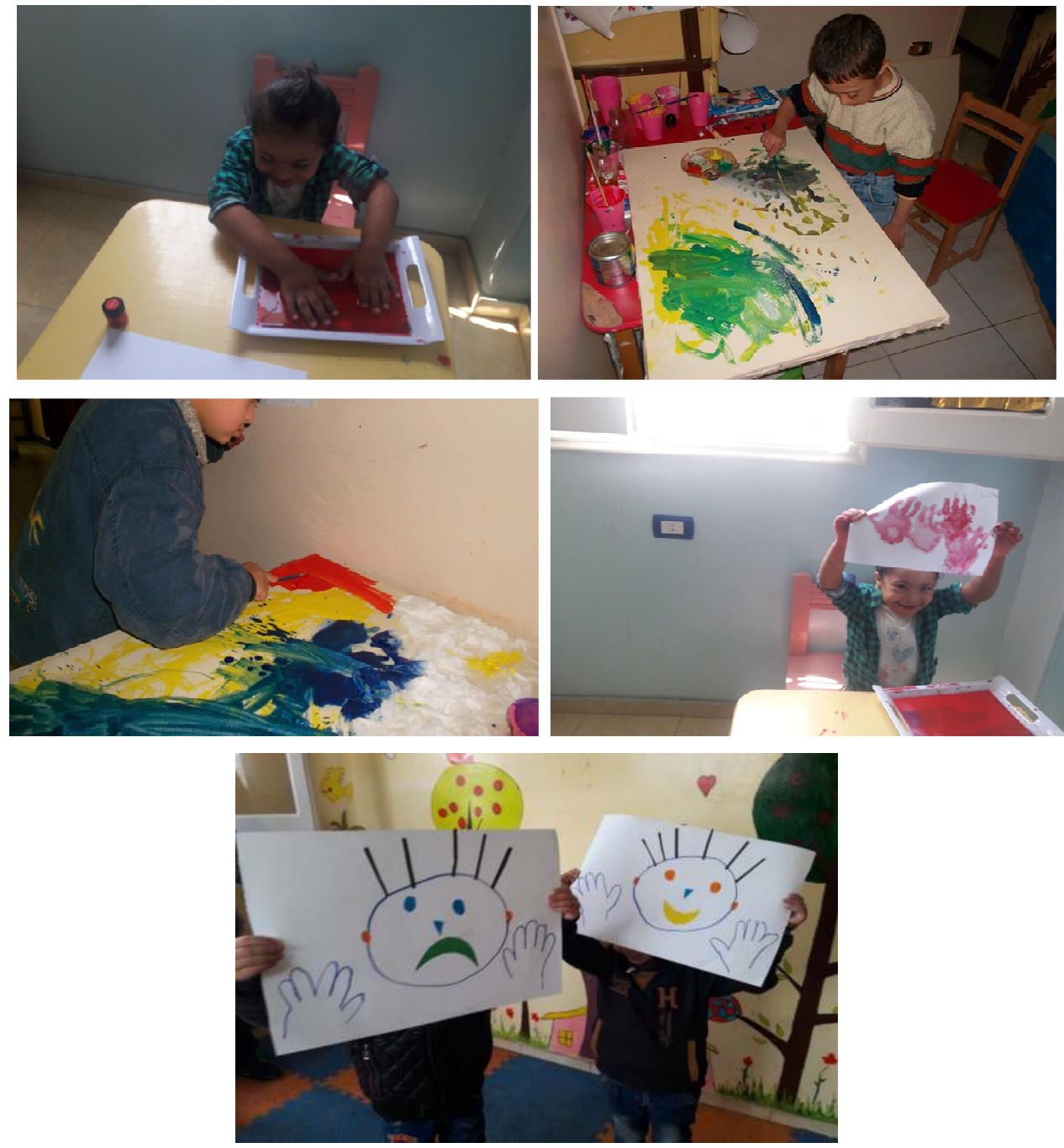


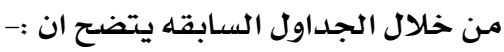

ا ـ يوجد فروق بين درجات مهارات التواصل اللفظى وغير اللفظى والتعبير الحر لدى عينه اطفـال

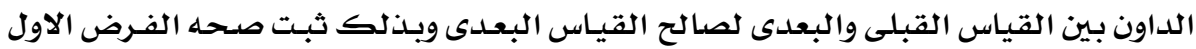

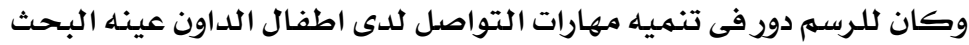

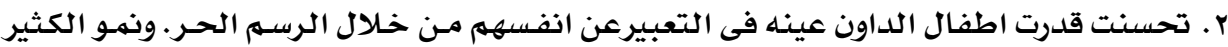

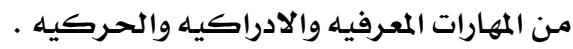
التوصيات

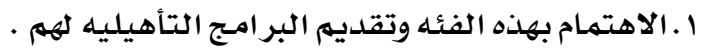

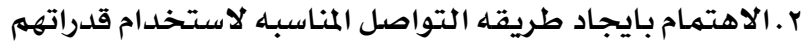

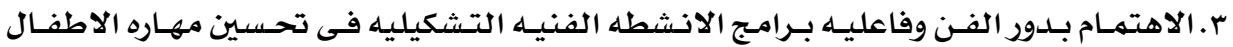

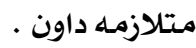

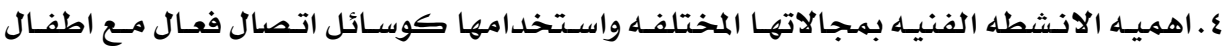

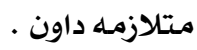

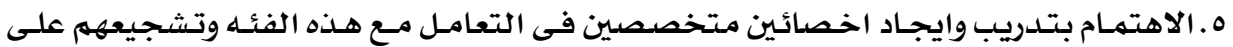

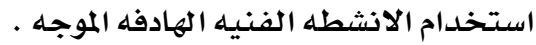




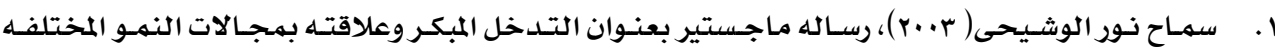

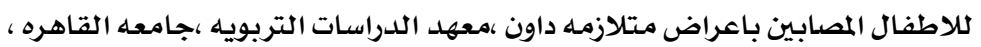

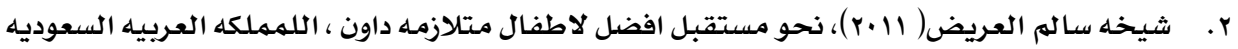

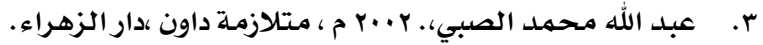

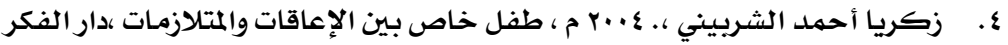

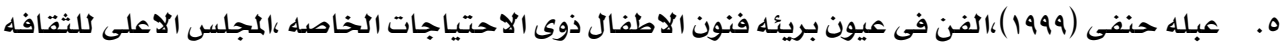

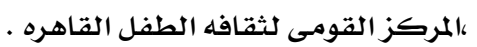

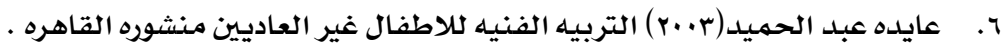

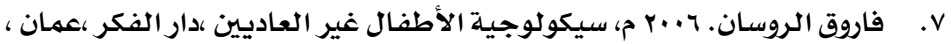

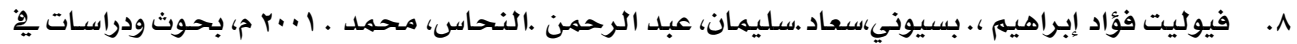

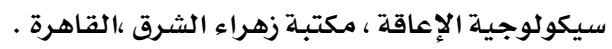

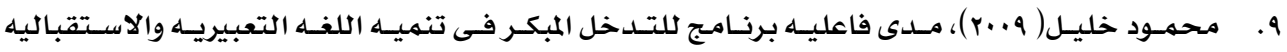

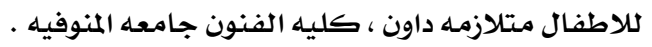

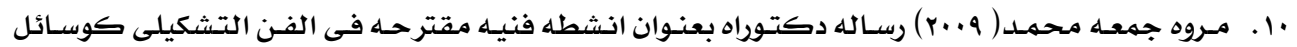

اتصال لتحسين مهارات التفاعل الاجتماعى ،كليه التربيه الفنيه ،جامعه حلوان .

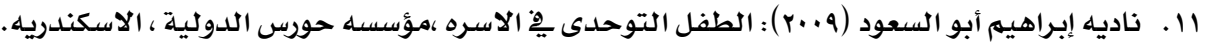

12. Aarons , M. \& Gittens, T.(1992): The handbook of autism : Aguide for parents and professionals. New York : Routledge

13. Greedon, Margaret P.(1993): Language development in non- verbal autistic children using a simultaneous communication sys-tem.paper presented at the Society for Research inchild de-velopment meeting :Philadelphia,March3

14. Emery, Melinda J.(2004): Art therapy as an intervention for Autisms: Autism Art therapy, yong children, child Development .case studies, language :Art therapy journal of the American Art therapy association .

15. Mary Colman,(1967):Oxford, UK :Blackwell Scientific publications-.

16. Osbourn, pat \& Scott, Fletcher(2004): Autism spectrum disorders: Guhdance on providing supports and service to young children with autism spectrum disorders and their families .New Mexico State Department of Education.

17. Fisch H, Hyun G, Golden R, Hensle TW, Olsson CA, Liberson GL.2003-

18. Malini SS, Ramachandra NB.2006, Influence of advanced age of maternal- 


\section{The Use Of Drawing and Free Expression in The Development}

\section{of Communication Skills of Children with Down Syndrome}

\section{Abstract}

The current research deals with the concept of Down syndrome and its symptoms, causes and characteristics and how to develop verbal and non-verbal communication and free expression by drawing their communication skills through a program of fine art prepared by the researcher and has been applied within two months on 4 children of Down syndrome aged (5:9) years in one of the centers specialized for the caring and rehabilitation of these children.

The researcher concluded through this research a total of pedagogical techniques in which we can Development verbal and nonverbal communication skills and free expression by drawing, also working on increasing language ,knowledge, cognitive ,kinetics and social skills. through what has been proven by the study hypotheses. 